\title{
CONTRIBUIÇÕES TECNOLÓGICAS PARA ELABORAÇÃO DE ATLAS ESCOLAR
}

\author{
TECHNOLOGICAL CONTRIBUTIONS TO SCHOOL ATLAS ELABORATION
}

\section{CONTRIBUCIONES TECNOLOGICAS A PREPARACIÓN DE ATLAS ESCOLAR}

\author{
Eduardo Pereira1 ${ }^{\text {; Lindon Fonseca Matias²; Suely Franco Siqueira Lima }}{ }^{3}$
}

\begin{abstract}
RESUMO
As tecnologias digitais estabeleceram um novo paradigma para elaboração e apresentação de atlas escolares, principalmente quanto a sua função no processo ensino-aprendizagem. Deste modo, se faz necessário conhecer os recursos que surgiram com os avanços tecnológicos e como eles podem ser aproveitados para o desenvolvimento deste tipo de atlas. Este trabalho apresenta tecnologias relacionadas a atlas digitais e contribuições pedagógicas do frameworkWeb2py e do API do Google Maps, na elaboração de atlas escolares. Com base na experiência da elaboração do protótipo "Atlas Ambiental da Cana-de-açúcar no Estado de São Paulo", são aqui destacadas as contribuições que esses recursos podem oferecer no desenvolvimento de atlas e em especial os escolares. Espera-se com este artigo evidenciar que é possível aproveitar os recursos tecnológicos disponíveis para elaborar esse tipo de material didático, que atenda às necessidades educacionais de hoje, bem como indicar um caminho metodológico na elaboração de novos atlas escolares.
\end{abstract}

PALAVRAS-CHAVE: Atlas escolar. Web2py. API do Google Maps. Aprendizagem.

\section{ABSTRACT}

Digital technologies have defined a new paradigm for preparing and presenting school atlas, mainly due to its role in the teaching-learning process. Thus, it is necessary to know the resources that emerged with technological advances and how they can be used to develop this type of educational material. This paper presents technologies related to digital atlas and educational contributions of web2py framework and Google Maps API, free softwares for developing school atlas. Based on the experience acquired during the preparation of the "Environmental atlas of sugarcane in São Paulo State", here are presented the contributions that these resources can provide in the development of school atlas. It is expected that this paper show that it is possible to take advantage of the technological resources available today to develop this kind of educational material that meets current needs, as well as indicate a methodological approach in the development of new school atlas.

KEYWORDS: School atlas. Web2py. API do Google Maps. Learning.

\footnotetext{
${ }^{1}$ Doutorado em Astrofísica - Instituto Nacional de Pesquisas Espaciais (INPE) - São José dos Campos, SP -Brasil. Graduação em Física - Universidade Federal de São João Del-Rey (UFSJ) - São João Del-Rey, MG -Brasil. Afiliado ao Instituto de Astronomia, Geofísica e Ciências Atmosféricas - Universidade de São Paulo (USP) - São Paulo, SP - Brasil. E-mail: pereira.somoza@gmail.com

${ }^{2}$ Doutor em Geografia Humana - Universidade de São Paulo (USP) - São Paulo, SP - Brasil. Professor Afiliado ao Instituto de Geociências da Universidade Estadual de Campinas (UNICAMP) - Campinas, SP - Brasil. E-mail: lindon@ige.unicamp.br

${ }^{3}$ Pós-Doutoranda em Geografia Física - Universidade de São Paulo (USP) - São Paulo, SP - Brasil. Doutora em Geografia - Universidade Estadual de Campinas (UNICAMP) - Campinas, SP - Brasil. E-mail: suelyfrancosiqueira@gmail.com.
} 


\section{RESUMEN}

Las tecnologías digitales han establecido un nuevo paradigma para la preparación y presentación de atlas escolares, sobre todo acerca de su papel en el proceso de enseñanza-aprendizaje. Por lo tanto, es necesario conocer las características que se incluyen con los avances tecnológicos y como pueden ser utilizados para desarrollar este tipo de atlas. En este artículo, se presentan las tecnologías relacionadas con los atlas digitales y las contribuciones educativas de la framework Web2py y API Google Maps, el software libre, el desarrollo del atlas escolar. Basado en la experiencia de la preparación del "Atlas ambiental de la caña de azúcar en el Estado de São Paulo", se resaltan aquí las contribuciones que estos recursos pueden aportar en el desarrollo del atlas escolar. Se espera que este artículo muestre que es posible sacar provecho de los recursos tecnológicos disponibles en la actualidad para desarrollar este tipo de materiales de enseñanza que respondan a las necesidades educativas de hoy, así como indicar un enfoque metodológico en el desarrollo de nuevos atlas escolares.

PALABRAS CLAVE: Atlas escolares. Web2py. API do Google Maps. Aprendizaje.

\section{INTRODUÇÃO}

A cultura digital traz um novo espaço de comunicação, sociabilidade, organização, transformação e conhecimento, exigindo uma reconfiguração dos espaços educacionais, de seus recursos e práticas pedagógicas. Entretanto, a exigência de transformação não deve ser entendida apenas como uma simples adequação às novas tecnologias, mas também, considerar as novas ecologias cognitivas que emergem na contemporaneidade em consequência do próprio avanço tecnológico (LOPES, 2012; SOUZA e SCHNEIDER, 2016).

Dentre os recursos educacionais que carecem de reconfiguração, destacamos os atlas escolares, cuja história de desenvolvimento está ligada a da Cartografia que, por sua vez, está atrelada à conquista e ao uso do espaço geográfico e ao desenvolvimento tecnológico. Apesar de a elaboração de representações cartográficas, em sentido amplo, ser uma prática antiga, anterior ao surgimento da escrita, os atlas, segundo Martinelli (2007), surgiram somente no início do século II como uma simples coletânea de mapas. O autor explica que, com o passar do tempo, os atlas foram se tornando mais complexos, recebendo textos geográficos e históricos que demandaram uma forma diferente de consulta, esboçando uma finalidade intelectual. Explica também, que com o avanço tecnológico e da internet, no final do século $X X$, surge uma variedade de tipos e versões de atlas eletrônicos que passam a apresentar recursos como animação e interatividade, privilegiando a multisensorialidade do usuário. Contudo, observamos que apesar dos avanços incorporados aos atlas escolares, estes não acompanharam a contento, as novas ecologias cognitivas de seus usuários, como destacado no artigo de Lima et al. (2015).

A organização de atlas digitais, assim como a de atlas impressos, segue concepção teórica e requisitos como base cartográfica, dados confiáveis, textos informativos, mapas temáticos diversos, glossário, índice e figuras. Os que envolvem novas tecnologias trazem no produto final novos conceitos como visualização cartográfica, multimídia, arquitetura das informações, animações, banco de dados e meios de distribuição (SAMPAIO et al., 2013). São

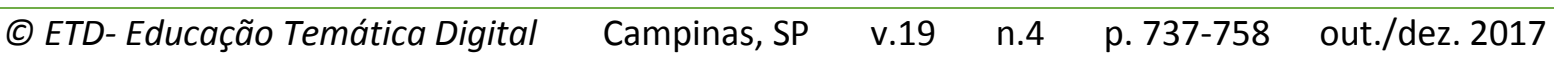


conceitos da tecnologia em si, mas que interferem no processo cognitivo do aluno como, por exemplo, no quão esses atlas estariam acessíveis aos jovens, na forma de conectar o conteúdo escolar ao atlas, na quantidade e no nível da interatividade oferecida, no nível de interação proporcionado e o quanto atraente e motivador será este tipo de atlas ao aluno. Estes novos conceitos precisam ser compreendidos pelos desenvolvedores de atlas, para que possam aproveitar, de forma eficiente, os recursos tecnológicos existentes e, assim, alcançar as novas ecologias cognitivas dos alunos.

Atualmente, o desenvolvimento de atlas pode contar com amplo espectro tecnológico, por exemplo, as geotecnologias que auxiliam na compreensão e na explicação da realidade em sua complexidade e dinamismo de forma atualizada e contextualizada, característica importante no contexto educacional. Porém, selecionar os recursos apropriados e usá-los adequadamente para elaborar atlas com o propósito educacional é uma tarefa interdisciplinar e difícil. Pois ela requer o conhecimento dos recursos tecnológicos existentes, dos conceitos inerentes a eles e de como estes podem ser aproveitados no desenvolvimento de atlas escolares de forma condizente com os novos regimes cognitivos. Como destacado por Lopes (2012), é necessário cuidado e compreensão epistemológica, pedagógica e social, para ir além da incorporação das tecnologias aos tradicionais processos de ensino-aprendizagem.

Nesse sentido, o artigo tem por objetivo apresentar a aplicação do framework Web2py e da Interface de Programação de Aplicativos (API) do Google Maps e destacar novos caminhos metodológicos na construção de atlas escolares. Também, apresentar a viabilidade da criação de atlas digitais, tendo como base uma equipe multidisciplinar. Para tanto são apresentadas suas contribuições no desenvolvimento do protótipo "Atlas Ambiental da Cana-

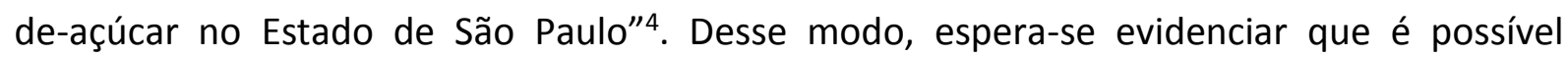
aproveitar as tecnologias digitais para elaborar atlas escolares compatíveis com as novas ecologias cognitivas dos alunos de hoje e, também, contribuir para suscitar inovações na elaboração dos mesmos.

Para maior compreensão do papel do framework Web2py e do API do Google Maps na construção de atlas escolares, é apresentado a seguir, uma revisão da literatura contemplando alguns conceitos inerentes à evolução tecnológica na área da visualização cartográfica e por consequência a construção de atlas.

\section{ATLAS DIGITAL E AS NOVAS TECNOLOGIAS}

A visualização cartográfica tem como missão facilitar a comunicação a um público abrangente e oferecer ao elaborador de mapas, ferramentas para tornar o mapa interativo, dinâmico e facilitador do raciocínio espacial e da resolução de problemas. Sua ênfase não é no armazenamento do conhecimento, mas sim na sua construção. Assim, apresenta como

${ }^{4}$ http://web2py.edupereira.webfactional.com/atlascana/default/index

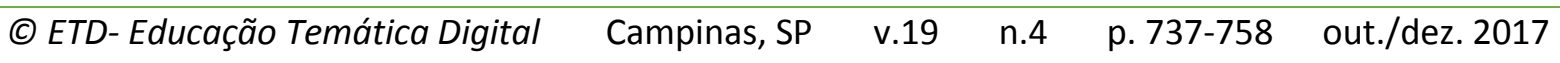


conceito chave a interatividade, a exploração, a interação usuário-banco de dados tendo o mapa como interface (RAMOS, 2005; SOUZA et al., 2016). Logo, não se pode pensar apenas em como fazer o mapa, mas principalmente em como será utilizado, quais instrumentos de análise serão fornecidos, nos mecanismos de exploração que serão disponibilizados e nas combinações de informações que o usuário poderá fazer.

Cabe aqui esclarecer a diferença entre interação e interatividade. Jensen (1988) explica que interatividade é uma palavra derivada de interação, que significa troca, influência mútua. Assim, para ser qualificada como interação, uma atividade deve ser interpretada pelos participantes. A interatividade, segundo este autor, é uma medida do potencial de uma mídia permitir ao usuário exercer uma influência sobre o conteúdo e/ou forma da comunicação. Tori (2010) define "interação" como a ação interativa em si e "interatividade" como uma propriedade do ambiente, tecnologia, sistema ou atividade. O autor explica que "(...) uma atividade pode ser interativa (possuir "interatividade"), independentemente das ocorrências efetivas de interações" (p. 5). Para ele, numa teleconferência em que é possível ao participante remoto interromper o apresentador para fazer perguntas possui mais interatividade que uma videoconferência unidirecional, mesmo que nenhum aluno se utilize da possibilidade de interação existente no primeiro caso. A preocupação de Primo (2005) é a que mais se aproxima aos objetivos de um atlas escolar. $O$ autor buscou entender o que acontece entre o emissor e o receptor na interação mediada pelo computador, considerando o processo cognitivo humano e analisando a interação dentro de um contexto. Nas suas palavras:

As tecnologias informáticas, mais do que um ferramental para acúmulo e circulação de informações, dão amplo suporte para a mediação de interações. (...) o conhecimento humano se dá na interação. Logo, tanto no contexto científico e educacional quanto no empresarial, o desenvolvimento dos saberes (individuais e de grupo como um todo) depende da comunicação. (PRIMO, 2005, p.397).

Deste modo, a visualização cartográfica deve proporcionar o maior nível possível de interatividade para que ocorra maior interação do usuário com a informação e, por consequência, construção do saber. Neste sentido, Cartwright et al. (2007) já apontavam a necessidade de as mídias evoluírem para incluir mais o elemento humano e apresentavam como possível solução o aprimoramento do software de Sistemas de Informação Geográfica (SIG). Para os autores, o SIG deveria oferecer componentes que propiciassem a interação do usuário e, para isso, tal recurso deveria passar da elite técnica para o usuário cotidiano, tornando-se mais intuitivo de usar, incluindo o argumento cultural e informações que destacam aspectos humanos e sociais que reflitam as metas básicas da sociedade. Ressaltavam que o principal é o acesso à informação e à elaboração do mapa de forma definida pelo usuário.

Hoje, no Sistema Web de Informação Geográfica (SIG-Web) o usuário acessa uma página com conteúdo cartográfico, hospedada em um servidor que realiza a leitura dos dados

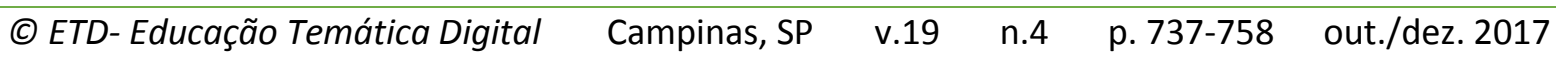


geográficos, efetua uma operação específica requisitada e converte o resultado desta operação em uma imagem que retorna ao usuário. Este acessa a página por meio de um browser de internet, onde é possível a aquisição de informações, análise e manuseio de dados com a possibilidade de criação e edição dos mapas na própria base de dados em ambiente identificado como "nuvem" (CASTRO e FERREIRA, 2012).

Cloud Computing (computação em nuvem): possibilita aplicações, aplicativos e infraestrutura como serviços para muitos usuários a partir de centros de dados distribuídos pela Internet. Os usuários podem utilizar diretamente os aplicativos baseados na Web (tais como Google Docs e Gmail, além ESRI ArcGIS Explorer online), ao invés de ter que baixar e instalar aplicativos em seu computador pessoal. Os programadores e desenvolvedores de aplicações podem também usar a computação em nuvem para criar servidores virtuais e plataformas de computação online para suas aplicações Web ao invés de manter para seus projetos equipamentos e servidores Web locais que são onerosos. (MENEGUETTE, 2012, p. 19)

Também existe a possibilidade do uso de programas computacionais livres, com código fonte aberta, tanto para a criação do SIG-Web, quanto para a construção de sites ou para um atlas multimídia, por exemplo. Isso traz uma grande vantagem, pois além da redução do valor final do aplicativo, possibilita a adaptação do programa criado às necessidades do usuário e à liberdade de distribuição, contribuindo para que o conhecimento se transforme em um bem social (GONZÁLEZ et al., 2006; PASSOS et al., 2008). Segundo Meneguette (2012), com o advento do software livre e de código aberto (FOSS - Free and Open Source Software) e das APIs de mapeamento livre na Web, os mapas podem ser produzidos e ou analisados também pelo cidadão comum.

O Application Programming Interface (API), em português, Interface de Programação de Aplicativos é um conjunto de padrões de programação que permite construir vários tipos de aplicações. Trata-se de uma plataforma gratuita de código aberto que permite usar o código original e adaptá-lo da maneira mais conveniente. Quando usado para criar um SIG, permite criar, integrar, publicar mapas, usar o sistema de dados existentes e incluir controles de interação do usuário com os mapas e dados espaciais que ficam hospedados em "nuvem" ou em endereço específico.

Outra questão importante para a visualização cartográfica e construção de atlas, como também já destacavam Cartwright et al. (2007), é a inserção das fotografias, texto livre, imagens de vídeo e som, como outros tipos de dados espaciais para auxiliar na tomada de decisões. A multimídia, segundo Ramos (2005), é a integração de diferentes formas de comunicação (mídias) e apresenta um grande potencial de transmissão de informações, principalmente a multimídia interativa, pois $60 \%$ das pessoas se lembram daquilo com que elas interagiram. Assim, a multimídia se torna um ambiente motivador e didático. Neste sentido, a arquitetura das informações exerce um papel importante na estrutura do atlas, 
pois, segundo Silva (2013), está relacionada à acessibilidade e à usabilidade ${ }^{5}$ de conteúdos informacionais. Ela funciona como uma espécie de fluxograma tecnológico para disponibilizar de modo eficaz conteúdos digitais, auxilia na organização das informações, na forma de apresentação e na criação de um sistema amigável de navegação. Para Ramos (2005), no processo da visualização, a arquitetura e o design de informação exercem importantes papéis, além de funcionar como faísca que inicia o fogo do conhecimento, fornecem a interatividade entre o usuário e a informação. Segundo Matos (2013), a interface com o usuário em qualquer sistema interativo apresenta papel relevante por potencializar o diálogo entre o sistema e o usuário e quanto maior for a usabilidade da interface, maior será a interação. Entretanto, como destacado por Carvalho (2003), o desenvolvimento de interfaces entre o ser humano e o computador é uma tarefa complexa devido ao aspecto humano na relação e exige estudos de abrangência interdisciplinar, e que é abordada na área de estudo Interação HumanoComputador $(\mathrm{IHC})^{6}$. Para Matos (2013), esta área aborda diversas correntes teóricas e metodológicas, tais como Engenharia Cognitiva, Engenharia Semiótica e a Engenharia Usabilidade. A alta qualidade da arquitetura de informação é fundamental para a comunicação e efetiva percepção da informação.

Assim, tornaram-se também um importante componente para a visualização cartográfica, o Free and Open (FOSS), por ampliar as possibilidades de interação e influenciar a forma de construção e apresentação de atlas. Como exemplo, frameworks que são estruturas de suporte definido em que um outro projeto de software pode ser organizado e desenvolvido. Estes recursos são projetados com a intenção de facilitar o desenvolvimento de software. Um framework é um conjunto de classes, interfaces e padrões para resolver um grupo de problemas. É como se fosse uma pequena aplicação com estruturas estáticas e dinâmicas com a finalidade de resolver um conjunto de problemas restritos. Desta forma, um framework é mais que uma simples biblioteca de rotinas de programação (FAYAD e SCHIMIDT, 1997; GOVONI, 1999; FAYAD, 2010). Esses recursos envolvem a combinação de linguagens de programação, cada uma delas especializada em um determinado aspecto. Para o chamado Front End que é a parte de visualização e interação final com o usuário são aplicadas, por exemplo, as linguagens Hyper Text Markup Language (HTML), Javascript e Cascading Style Sheets (CSS). Para o Back End, que é a parte de programação que roda em um servidor e é usado para gerenciar o processo de construção dinâmica do site, são usadas, por exemplo, as linguagens Hypertext Preprocessor (PHP), Python, Ruby.

\footnotetext{
${ }^{5}$ Usabilidade é uma característica de um programa de computador que considera a interatividade, a aprendizagem e a performance do usuário e, quanto ao mecanismo de qualidade de software, depende de um acordo entre as características de sua interface coma as características/necessidades dos usuários.

${ }^{6}$ Interação Humano-Computador (IHC): área do conhecimento relacionada ao projeto, avaliação e implementação de sistemas computacionais interativos e dos fenômenos que o cercam (UNITED STATES, 1992, p. 5).
}

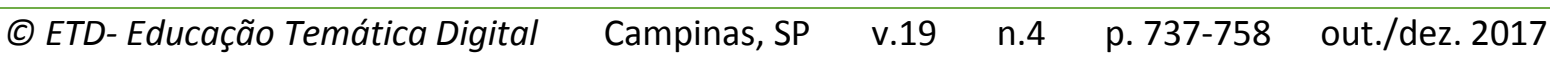


Quanto às animações, Ramos (2005) ressalta que estes recursos quando utilizados com critério, enriquecem o atlas. A autora entende por animação uma sequência de imagens, instantâneas ou desenhos que, quando executados, permitem a impressão de movimento. Esta sequência de imagens é montada em softwares específicos e a autora a classifica em animação interativa, a que permite que o usuário ao apontar uma feição da imagem, obtenha algum resultado, em forma de imagem, texto, áudio, ou outra animação a ser exibida. Já para Martinelli (2005), animação é qualquer apresentação em movimento, seja por filme, vídeo, computador, que mostram mudanças com variação de tempo, espaço e atributo e vai além da apresentação de séries de imagens sequenciadas. Para ele a animação pode ficar apenas na apresentação (o observador não tem controle sobre o andamento da exibição) ou ser interativa (o usuário tem domínio e pode intervir na exibição).

Tratando mais especificamente da animação cartográfica, Ramos (2005), descreve-a como forma de analisar melhor a dinâmica espacial (temporal ou não), representadas em mapas, por meio da comparação entre eles. Com o recurso da animação dos mapas, as mudanças ficam mais evidentes do que quando analisado o mapa individualmente. A autora considera três tipos de animação cartográfica: I) temporais (representam mudanças de atributos e localização de feições ao longo do tempo. Ex: animação de imagens meteorológicas, por interpolação de dados); II) não temporais (expressa o comportamento de uma série de dados que oferecem diferentes pontos de vista do mesmo espaço, independentemente do tempo. Ex: um voo simulado, modelagem em 3D, rotação de um modelo digital de elevação); III) de construção interativa (é feita com a sobreposição de sucessivos layers para explicar um fenômeno. Ex: mapas sobrepostos de relevo, hidrografia, vegetação etc.). A animação oferece ao usuário a oportunidade de ver e consultar mudanças nos padrões espaciais com melhor compreensão dos fenômenos mapeados e os recursos hoje disponíveis possibilita ao usuário as opções apropriadas para interação.

Com os modernos sistemas de transmissão de dados, compostos por satélites, fibra ótica e a telefonia surgiram as infovias que suportam a transmissão de grande quantidade de dados (RAMOS, 2005). Portanto, deve-se considerar para elaborar um atlas digital qual será o seu meio de distribuição.

Ramos (2005) esclarece que as tecnologias digitais alteram a forma de distribuição das multimídias e destaca dois meios de distribuição, a mídia discreta (dispositivo em que a aplicação será gravada e distribuída fisicamente ao usuário) e a rede (a aplicação é distribuída por meio de sistema de telecomunicações). Entretanto, as mídias discretas estão entrando em desuso e os equipamentos de última geração também não contemplam mais leitores de CDs e DVDs. Assim, como ressaltado por Ramos (2005), a internet passou a ser o maior e mais eficiente meio de distribuição de representações da cartografia, por ser um meio de comunicação de massa, por apresentar a possibilidade de interação, por permitir a atualização em tempo real dos dados que podem, em segundos, ser acessado de qualquer parte do 
mundo. Esta autora define a internet como um sistema de transferência de arquivos entre computadores, arquivos estes que estruturados como números no sistema binário, podem assumir a forma de textos, gráficos, imagens, entre outras.

Inicialmente a linguagem padrão para a construção da World Wide Web (WWW), é a HyperText Markup Language (HTML) e é localizada por um sistema de endereçamento chamado Uniform Resource Locator (URL). Os arquivos gráficos, estáticos ou animados, são inseridos na Web nos formatos Graphics Interchange Format (GIF), Joint Photographics Experts Group (JPG), Basic Metabolic Panel (BMP), Portable Network Graphics (PNG), Tagged Image File Format (TIF) etc. (RAMOS, 2005).

Para Cartwright et al. (2007) a Web surgiu como uma das principais formas de distribuição de determinados tipos de mapas, principalmente de mapas interativos. Neste sentido, surgiram estudos que buscaram explorar o potencial da internet para combinar conteúdo multimídia com mapas, explorando a criação de uma multimídia SIG baseado na Web, que é baseada na interação de três componentes: I) um aplicativo SIG baseado na Web desenvolvido para manipular mapas digitais; II) uma aplicação multimídia interativa baseada na Web projetada para manipular a informação multimídia, incluindo hipertexto, hiperlinks, gráficos, fotografias, vídeo e som digital; e III) um mecanismo que liga a aplicação SIG baseado na Web e a aplicação multimídia interativa (CARTWRIGHT et al. 2007).

$\mathrm{Na}$ interpretação de Meneguette (2012), a Web é a nova mídia dos mapas, que transforma a representação cartográfica do papel e do Sistema de Informação Geográfica (SIG) desktop em serviços de informação geoespacial distribuídos e centrados no usuário, nos dispositivos móveis e em tempo real.

Entretanto, como destacado por Di Maio e Setzer (2011), para o uso generalizado de geotecnologias combinadas com a informática, ainda existem desafios a serem superados pela rede de ensino no Brasil. Os autores salientam que apesar da disponibilidade de dados e programas gratuitos na internet, há desafios relacionados aos laboratórios de informática das escolas, a formação de professores no uso de novas tecnologias e o desenvolvimento de materiais adequados para fins educacionais no ensino básico. Essas dificuldades podem ser observadas na fala de Nunes (2016):

\footnotetext{
"Quando estava planejando as atividades desta pesquisa, eu imaginava que não haveria problema algum em realizar essas atividades numa escola de ensino fundamental ou médio. Mas quando eu entrei em contato com a direção de algumas escolas a fim de expor as características da pesquisa e, principalmente, solicitar consentimento para a efetuação das atividades com a participação de alunos, recebi respostas negativas ou imposição de condições que alterariam muito o arcabouço do trabalho" (NUNES, 2016, p 893).
} 
"Infelizmente a escola não possuía uma sala de aula com computadores conectados na internet especificamente destinada para o desenvolvimento de atividades de ensino. Dessa maneira, sem ter esse tipo de espaço à disposição, tornou-se inviável efetuar a reunião com os alunos, logo após a caminhada, para fazer a anexação das fotografias ao mapa do sítio do Google" (NUNES, 2016, p 893).

Contudo, é observado que o próprio avanço tecnológico tem apresentado soluções e tornado a visualização cartográfica mais popular e acessível à comunidade educacional. Limitações nos "hardware" disponíveis nas escolas ou por burocracias próprias das escolas, como autorização para a instalação de software nas máquinas da escola, conforme sugerido por Castro e Ferreira (2012), podem ser facilitadas, usando as funcionalidades de um SIG online, cuja base de dados fica em ambiente identificado como nuvem. Isso possibilita o acesso, a criação e a edição de mapas, não havendo necessidade de um software instalado no computador da escola e ou muito espaço na memória do computador, além de contribuir para o educador gastar menos tempo em download de software, banco de dados e em capacitação para seu uso (LIMA et al., 2013).

Outro aspecto que tem contribuído para facilitar o uso das geotecnologias são os dispositivos móveis que promovem a ubiquidade desses recursos, libertando o educador e aluno dos laboratórios de informática. Isso, pode ser observado em alguns trabalhos, como exemplo, o trabalho de Nunes (2016) que analisa as possibilidades de uso dos smartphones em situações escolares de aprendizagem.

Com base no exposto e no tópico seguinte, verifica-se que existem as ferramentas necessárias para elaborar um atlas escolar que estimule, motive e crie um ambiente que proporcione a efetiva interação do sujeito com o objeto do conhecimento, utilizando os recursos disponíveis nas escolas ou fora delas.

\section{WEB2PY COMO FERRAMENTA PARA ELABORAR PLATAFORMA DE ATLAS}

Usar o framework Web2py para construir a plataforma de um atlas é uma opção bastante interessante. Além de ser gratuito, este framework é de fácil manutenção e permite a construção de um site dinâmico e personalizado. Essas funcionalidades são importantes para o contexto pedagógico, pois permitem elaborar interface e designer gráfico que sejam atraentes aos alunos e com características direcionadas aos propósitos dos projetos didáticosociais, garante acessibilidade aos alunos de aprendizagem ubíqua dentro ou fora da escola e possibilita reunir vários bancos de dados para compor um ambiente rico em interatividade e interação.

${ }^{7}$ Web2py - software livre e gratuito cuja autoria é de Massimo Di Pierro.

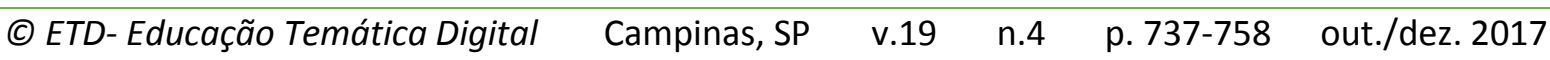


Estas características foram comprovadas na construção do protótipo do Atlas Ambiental da Cana-de-açúcar no Estado de São Paulo. Cabe ressaltar que a construção do protótipo buscou caminhos para tornar um atlas escolar atraente e motivador aos alunos. Para isso, embasou-se na proposta metodológica de ir além da transmissão de informação e trazer o educador e o aluno como sujeito no processo ensino-aprendizagem com o auxílio de um SIGWeb personalizado e da inserção de um jogo com características edutainment. O jogo é quem faz a interlocução entre os conteúdos do atlas: o SIG, o texto e o próprio jogo e entre esses e o aluno.

A plataforma do protótipo do Atlas foi construída usando o Framework web2py, versão 2.8.2 na linguagem de programação Python, que permite a visualização do atlas em qualquer navegador da web e também em diferentes dispositivos como celulares, tabletes e computadores. Ela está alocada em nuvem em um servidor particular, mas pode ficar alocada em qualquer servidor de interesse do autor do atlas. Isso viabiliza a visualização e manipulação do conteúdo do atlas sem a necessidade de baixar arquivos na máquina do usuário ou, mais especificamente, nos computadores da escola.

A plataforma criada, possui três janelas principais, a primeira janela (home) (Figura 1) é a entrada para o Atlas e apresenta além das informações referentes aos autores e colaboradores, três botões que são: Registrar-se, Atlas e Jogo.

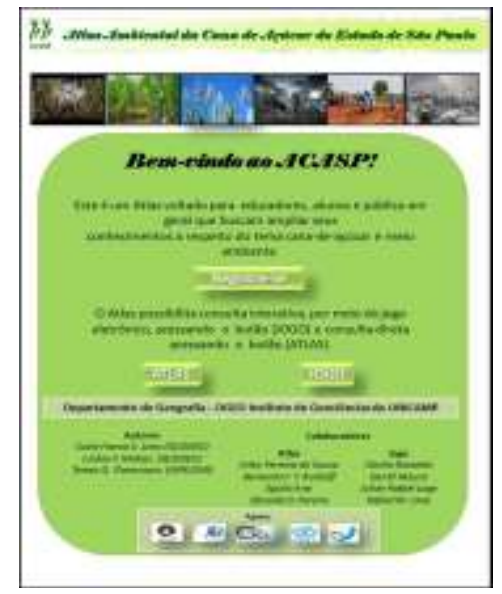

FIGURA 1 - Página de abertura do protótipo do Atlas.

Fonte: Lima 2015

O botão "Registrar-se" foi criado com o objetivo de obter uma avaliação quantitativa do Atlas como, número de usuários, número de acessos ao Atlas e ou ao Jogo, localização dos usuários e faixa etária do usuário. Outros itens de avaliação poderão ser inseridos futuramente para avaliar o contexto pedagógico, por exemplo, até que nível do Jogo (conteúdo programático) o usuário chegou. Os demais botões são atalho para a página com

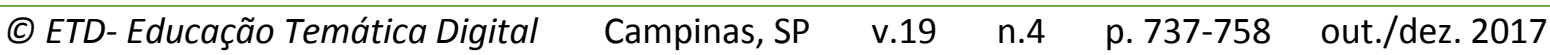


jogo (Jogo) ou sem jogo (Atlas), para atender tanto ao interesse do aluno quanto ao do educador que pode trabalhar com o atlas sem ter que acessar o jogo. A página com o jogo buscou atrair o interesse do jovem e lhe proporcionar estrutura para a construção de seu saber (aprendizagem). Ela está dividida em três partes e dá ênfase ao jogo (Figura 2).

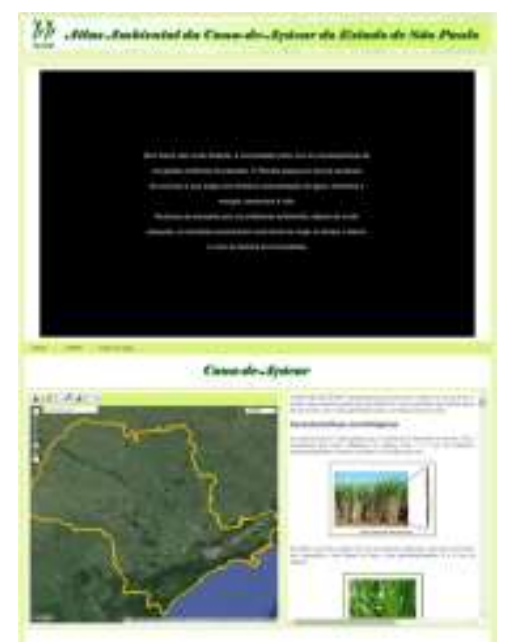

FIGURA 2 - Leiaute da página com o jogo para o protótipo do Atlas.

Fonte: Lima 2015

As grades foram construídas de modo que, quando acessada esta página, o jogo ocupa quase o monitor todo. $O$ objetivo disso foi de deixar maior área para o jogo a fim de criar maior grau de imersão e concentração. Também, as informações do Atlas mantiveram-se na mesma página, evitando que o jogador (aluno) ao sair da página para buscar o conteúdo do Atlas, se entretenha com outros atrativos da internet. Assim, para o jogador (aluno) acessar as informações nos textos e mapas sem mudar de página, foi criada uma barra de rolagem exibindo na mesma página o jogo, texto e o SIG. Nessa página, também foram inseridos os links para a próxima fase do jogo, que também corresponde aos próximos temas do Atlas, para a página de início do Atlas (Home) e para acesso ao dispositivo de ajuda. No dispositivo de ajuda, serão fornecidas informações para ajudar o usuário a realizar as atividades no SIG e no jogo. Esta formatação é específica para o usuário do Atlas o qual deseja jogar, mas se a opção do usuário é apenas fazer consulta este não é o melhor leiaute. Por isto, foi criada outra página dividida em duas grades (Figura 3) que omite o jogo e dá ênfase ao SIG e ao texto. 


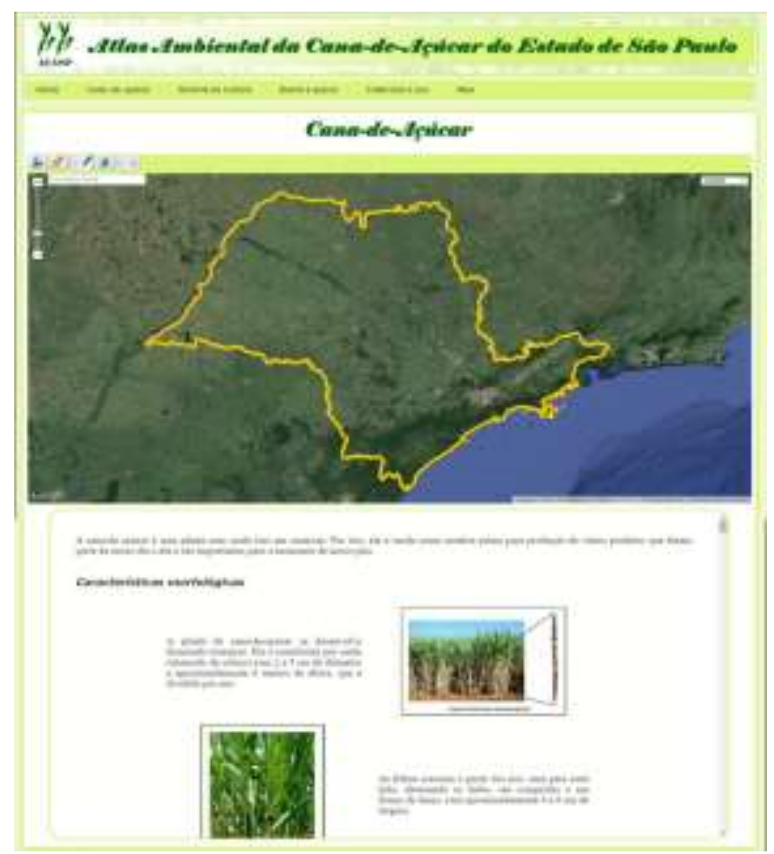

FIGURA 3 - Leiaute da página sem o jogo.

Fonte: Lima 2015

De forma geral a plataforma do protótipo foi criada em três camadas, sendo o Python para o gerenciamento das páginas, HTML e CSS para a edição de texto e design, finalmente o JavaScript para a construção do SIG. Essa é outra característica bastante interessante deste framework, pois poder fazer uso de várias linguagens de programação permite construir o atlas em etapas diferentes e separadas, permitindo o envolvimento de vários profissionais de diferentes áreas do conhecimento. Por exemplo, um educador que mesmo sem conhecer linguagem de programação pode gerar o conteúdo do atlas na forma de texto, tabelas, figuras e vídeos, usando um editor de texto de alto nível ${ }^{8}$ e salvando em formato de arquivo HTML, para depois ser inserido na plataforma do atlas pelo programador. Desta maneira, fica garantida a inserção dos conteúdos programáticos escolares na temática abordada pelo atlas e a busca de ir além da transmissão de informação, realçando a relação sujeito/objeto, proporcionando um ambiente para a construção do conhecimento, como nos ensina Pino (2001) e Freire (1983 e 1996). É importante contar com a ajuda de um profissional da educação, para fazer a adequação desse conteúdo, pois, como ressaltado por Almeida (2003), se o problema do cartógrafo é mapear o local, o do professor é ensinar o local, considerando as necessidades da comunidade escolar e o currículo escolar.

\footnotetext{
${ }^{8}$ Alto Nível se refere ao desenvolver algo mais próximo da linguagem humana do que na linguagem de máquina. Como exemplo de editor de alto nível pode-se citar o Libre Office Writer, que permite exportar um texto para o formato HTML.
}

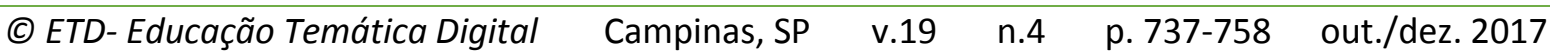


O grande diferencial desse framework é que ele usa Database abstract layer (camada de abstração de banco de dados) e isso permite a interação com vários bancos de dados sem ter que mudar o código originalmente desenvolvido, permitindo migrar de um banco de dados para outro. Com isso, é possível agregar ao atlas maior grau de interatividade e imersão por meio, por exemplo, do uso de geotecnologias e de jogo com nível mais elevado de complexidade, em representação tridimensional (3D).

É possível verificar este diferencial no caráter lúdico proporcionado pelo jogo ao Atlas e também a interlocução do usuário com seu conteúdo, de modo a formar um ambiente que contribui para a aprendizagem sobre a cultura de cana-de-açúcar e suas interferências ambientais. Como exemplo da interlocução do jogo com o Atlas, pode-se citar a passagem em que Ícaro (personagem vivido pelo jogador), durante uma conversa com outro personagem, recebe uma mensagem sobre a chegada de um robô, como mostra a Figura 4.A. O jogador terá que se dirigir até a sala preparada para ele e acessar um computador que apresenta um roteiro de atividades para serem realizadas no Atlas (Figura 4.B). É solicitado ao jogador ir até os mapas do Atlas; digitar as coordenadas indicadas; inserir o mapa com a divisão municipal para descobrir em que município ele deverá ir buscar o robô (personagem que auxilia o jogador na sua aprendizagem); ampliar a área e descobrir se existem rodovias e área urbana próxima ao local indicado, para resgatar o robô e; inserir o mapa de cultivo de cana-de-açúcar para verificar se existe cultivo próximo ao local de resgate. Essas tarefas são para responder as três questões que se encontram na tela do computador no jogo: Qual é a cidade? Existe uma área urbana neste local? Existem plantações de cana neste local? Estas questões devem ser respondidas corretamente para o jogador avançar no jogo. Neste momento o cursor é liberado para o jogador, por meio da barra de rolagem, acessar o conteúdo do Atlas (Figura 4.C). Seguindo as primeiras tarefas, o jogador visualiza o mapa do limite do estado de São Paulo (mapa do banco de dados do Atlas) sobreposto no mosaico de imagens de satélite, o marcador indicando o local (base de dados do Google), o mapa da divisão administrativa dos municípios do estado de São Paulo (mapa do banco de dados do Atlas) e o mapa de cultivo de cana-de-açúcar do estado de São Paulo (mapa do banco de dados do Atlas) (Figura 4.D). O objetivo desta atividade é ensinar o jogador a trafegar entre o jogo e o Atlas, promover a familiaridade do jogador com os recursos disponibilizados no SIG, com dados de sensoriamento remoto e com mapas de cultivo de cana-de-açúcar. 


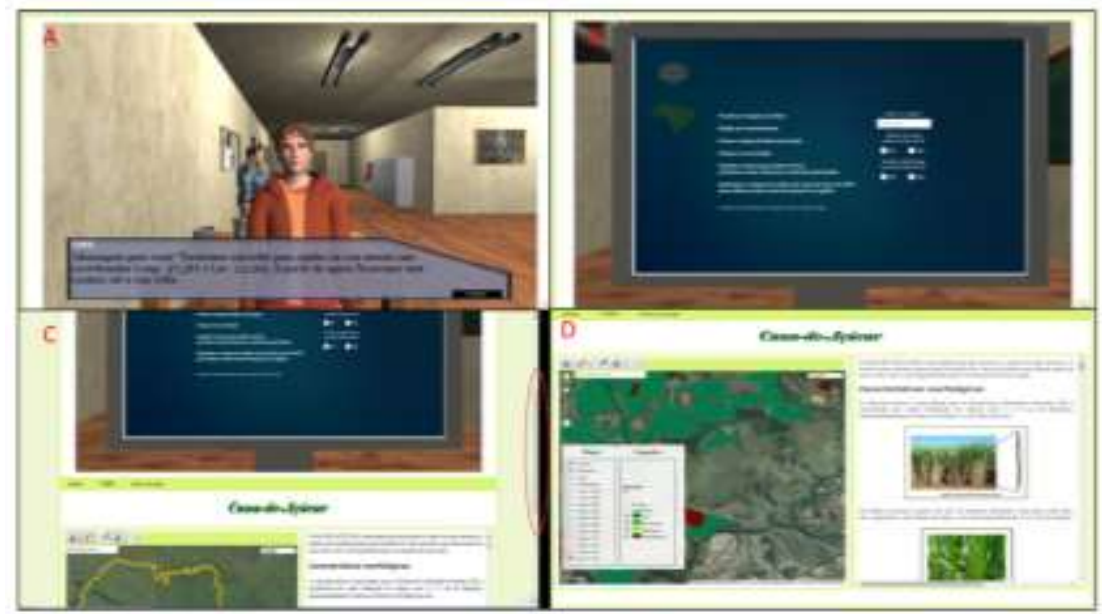

FIGURA 4 - Visualização das janelas do jogo e do SIG e do texto que compõem o Atlas. Fonte: Lima 2015

O desenvolvimento de atlas com o uso de jogos eletrônicos como recurso educacional coloca o aluno (jogador) como responsável pela sua aprendizagem e permite criar ambientes que simulem a realidade em que estão inseridos de forma lúdica, estimulando o reconhecimento dos problemas do mundo atual e também intervir e promover as transformações necessárias. Estas possibilidades salientam os jogos eletrônicos e, por consequência o atlas, como um recurso educacional em consonância com diretrizes educacionais como a metodologia ativa e a pedagogia da problematização abordada por Freire $(1983 ; 1996)$ e Dewey (1997), entre outras referências.

Como destacado por Oliveira (2012), é possível verificar que as interfaces gráficas reconfiguram novas formas de associação e de agregação nos ambientes digitais e a cada nova tecnologia, novas configurações cognitivas vão sendo construídas sutilmente na inter-relação entre o homem e o meio artificialmente projetado. Assim, o uso do framework Web2py permite a associação e agregação dos ambientes digitais criando mecanismos que proporcionam alto nível de interação entre o aluno e o objeto de conhecimento e inserção de inovações pedagógicas nos atlas escolares. Cabe ressaltar que para resultados mais eficientes, é importante, antes de iniciar a construção da plataforma do atlas, fazer um estudo prévio dos requisitos e características que seriam desejáveis na interface e no designer gráfico para o público alvo.

\section{API DO GOOGLE MAPS PARA A CONSTRUÇÃO DE UM SIG}

A importância do uso das geotecnologias no ensino é discutida e exemplificada por Lima et al. (2007, 2009, 2011), Florenzano (2007), Moraes e Florenzano (2007), Di Maio (2004) Di Maio et al. (2009), Di Maio e Setzer (2011), Carvalho (2012), entre outros. Para Di Maio e

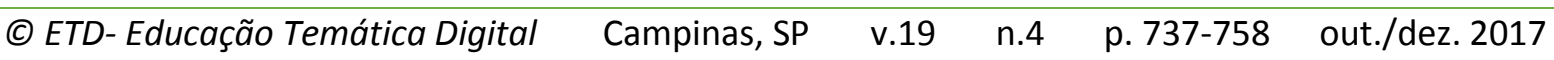


Setzer (2011) o trinômio formado pela integração do sensoriamento remoto, com SIG e com a cartografia digital, revela um forte potencial didático pedagógico. Deste modo, a construção de atlas com o uso de um SIG, permite que o usuário sobreponha dados para análise, gere novas informações e principalmente que ele acesse e organize as informações de acordo com seu nível e necessidades cognitivas. Também, como exposto por Freire e Valente (2001), a tecnologia pode ser usada para facilitar a compreensão e interpretação de fenômenos socioculturais e estimular o envolvimento do aluno em atividades sociais relevantes. Esse conjunto de recursos oferece a possibilidade de contextualizar e atualizar as mudanças do meio ambiente, característica importante na prática educacional (LIMA, 2008). As geotecnologias contribuem para a obtenção, análise e interpretação de dados e remetem a dimensões do tempo e do espaço, essenciais na compreensão dos problemas ambientais e no estudo do processo de ocupação e transformação do espaço geográfico. Elas são, sem dúvida, o caminho para inserir nos atlas a abordagem construtivista, mas ainda, é necessário buscar mecanismos para torná-las mais acessíveis e amigáveis aos olhos dos educadores e alunos.

Neste sentido, o API do Google Maps traz grande contribuição, pois é uma plataforma gratuita de código aberto que permite usar o código original e adaptá-lo da maneira mais conveniente para criar, integrar, publicar mapas e também usar o sistema de dados existentes na plataforma Google Maps. Esse recurso é viável considerando, como já mencionado, que o público alvo não tem familiaridade com softwares de Sistemas de Informação Geográfica. Ele permite criar um SIG que pode ser inserido em atlas que mantém a característica visual e funcionalidades similares as do Google Maps e Google Earth, que são familiares a maioria dos usuários, principalmente o público mais jovem, que está habituado a navegar nesses aplicativos. Também, permite adaptá-lo de maneira conveniente às necessidades do atlas e do público alvo. Isto é, permite inserir apenas as ferramentas necessárias para a visualização e manuseio do banco de dados espaciais do atlas, reduzindo a confusão que vários botões (funções), disponíveis na interface gráfica, causam ao usuário não familiarizado com SIG (Figura 5).

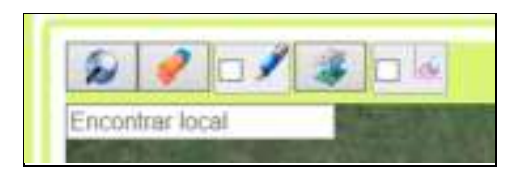

FIGURA 5 - Botões construídos para compor o SIG.

Fonte: Lima 2015

Desse modo, é possível ao usuário visualizar os mapas do atlas de forma independente ou sobrepostos ao sistema de dados existentes do Google Maps, fazer a sobreposição de dados espaciais, análises, cálculos e gerar novas informações. Tais possibilidades, inseridas em um atlas escolar, proporcionam mais interatividade e, por consequência, mais interação, contribuindo para a construção do conhecimento. Como ressaltado por Freire (1983), 
conhecer não é o ato através do qual um sujeito, transformado em objeto, recebe, dócil e passivamente, os conteúdos que outros lhe dão ou impõe. Para ele, conhecer é tarefa do sujeito e somente enquanto sujeito o homem pode realmente conhecer.

No protótipo, por exemplo, foi inserido o botão "criar polígono" que permite delimitar área e calcular em hectares, conforme mostra a Figura 6. Ao clicar neste botão e depois no mapa, aparecem os marcadores em cada clique que usar para contornar uma área desejada. Quando finalizada a delimitação de uma área, basta clicar dentro dela para o programa fazer o cálculo do polígono criado em hectares e mostrar na tela.

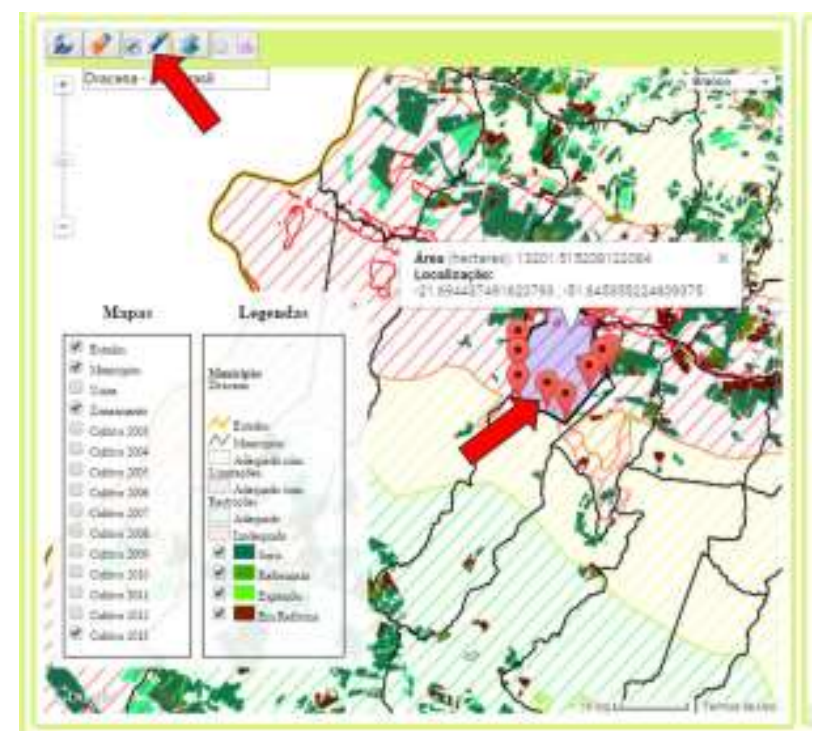

FIGURA 6 - Botão "criar polígono" para a atividade de encontrar maior área possível em região considerada inadequada pelo Zoneamento Agroambiental.

Fonte: Lima 2015

Este recurso foi criado para a atividade em que o jogador, para convencer o inimigo de que é, como ele, transgressor da lei, deve encontrar um local no município de Dracena com maior área possível para cultivo de cana-de-açúcar, mas tem que ser numa área considerada inadequada pelo Zoneamento Agroambiental. Esta atividade tem por objetivo apresentar o mapa do Zoneamento Agroambiental e destacar sua importância no contexto ambiental.

Cabe ressaltar que essas possibilidades contribuem para a inclusão do elemento humano na mídia e a popularização do SIG, pois proporcionam a comunicação e a efetiva percepção da informação. Também oferecem ao usuário opções apropriadas para interação e oportunidade de ver e consultar mudanças nos padrões espaciais com melhor compreensão dos fenômenos mapeados. 
A API do Google Maps, apresenta características bastante relevantes ao possibilitar o desenvolvimento de um SIG-Web, que permite o acesso, a criação e a edição de mapas em "nuvem"; e desenvolvero SIG para qualquer plataforma Web, Android, iOS e servidor, característica que precisa ser levada em conta, considerando a popularização dos celulares conectados à internet, que estão cada vez mais frequentes nas mãos dos jovens, inclusive naqueles de escolas públicas. Como destacado por Souza e Schneider (2016), as Tecnologias Digitais de Informação e Comunicação (TDIC) vêm ganhando espaço no cotidiano de crianças e jovens. Deste modo, também contribuem para solucionar problemas enfrentados no contexto escolar, como os exemplos já mencionado neste trabalho: a necessidade de autorização da direção da escola para instalar programas nas máquinas do laboratório de informática, as limitações quanto aos computadores, por exemplo, quantidade disponível, máquinas com pouca memória e etc.

Di Maio e Setzer (2011) destacam que o uso da tecnologia educacional pode ser uma oportunidade de escolarização para os menos favorecidos, pois por meio dela se aprende não apenas na sala de aula, mas também em casa, ou em qualquer lugar com acesso à informação. Eles ressaltam, no entanto, que isto não tira das instituições educacionais (públicas ou privadas) o seu papel de educar e de preparar o aluno para desempenhar funções numa sociedade cada vez mais tecnológica e da informação.

Viabilizar o uso das geotecnologias dentro de um atlas para o público educacional, envolve compreender suas necessidades, considerar suas limitações e apresentar soluções. Neste sentido, o API do Google Maps pode ajudar a solucionar problemas de adequação do SIG para o público educacional, tanto na forma de apresentação como na forma de disponibilização.

\section{CONSIDERAÇÕES FINAIS}

Os avanços tecnológicos ao mesmo tempo em que exigem dos atlas mudança de paradigma oferecem recursos inovadores para a sua elaboração. Porém, não é fácil saber quais desses recursos e de que forma podem ser utilizados para promover mudanças que tragam efetiva contribuição para aprimorá-los e, em especial, no caso dos atlas escolares, que acrescentem inovações também de caráter pedagógico.

A partir do aqui exposto, pode-se concluir que na elaboração de um atlas escolar dois elementos são essenciais: a interatividade e os recursos geotecnológicos. A interatividade por permitir, através de variados periféricos, menus e links audiovisuais a troca entre máquinas, software e usuários, por propiciar a aquisição de informação e comunicação por meio de possibilidades variadas de escolha e feedbacks, opções de transformação do ambiente virtual

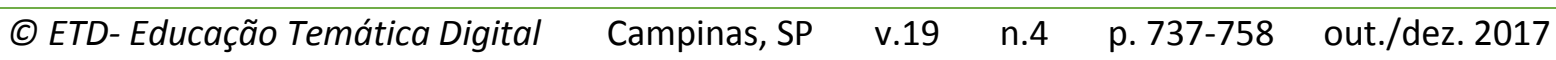


de acordo com as necessidades e preferências do usuário e por garantir a imersão e entretenimento. Os recursos geotecnológicos são excelentes aliados no processo da aprendizagem, pois além de facilitar a interatividade, promovem a observação analítica do espaço geográfico e a construção de um sistema intelectual a partir de uma realidade apresentada de forma diversificada. Eles ajudam a criar novas informações e a reflexão necessária para a compreensão das mudanças e das novas configurações estruturais do mundo contemporâneo. Nesse sentido, os softwares livres Web2py e API do Google Maps, se mostram como grandes aliados, pois ambos apresentam mecanismos que possibilitam aumentar a interatividade, de forma a garantir um ambiente que contribua para a efetiva interação e aprendizagem.

Espera-se com este artigo, mostrar a viabilidade de construção de atlas digitais usando o que há de mais moderno, em termos tecnológicos, a um baixo custo. Assim, espera-se contribuir para motivar e subsidiar a elaboração de novos atlas escolares que proporcionem ambiente para a construção do conhecimento e contemplem as novas ecologias cognitivas dos alunos de hoje.

\section{REFERÊNCIAS}

ADITYA, Trias; KRAAK, Menno Jan. National atlas metaphor in the access to the GDI. In: PROCEEDINGS OF THE 7 TH INTERNATIONAL CONFERENCE: GLOBAL SPATIAL DATA INFRASTRUCTURE GSDI, Bangalore - India, 2004. Anais... Bangalore, 2004. p.1-19.

ALMEIDA, Rosângela Doin de. Atlas municipais elaborados por professores: A experiência conjuntade Limeira, Cad. Cedes. Campinas, SP. 2003. v. 23, n. 60, p. 149-168.

CARTWRIGHT, William; PETERSON, Michael P.; GARTNER, Gartner. Multimedia Cartography. New York: Springer Berlin Heidelberg. 2007. 546 p.

CARVALHO, José Oscar Fontanini de. O papel da interação humano-computador na inclusão digital. Transinformação, n.15, ed. esp., 2003 p. 2003. 75-89.

CARVALHO, Vania Maria Salomon Guaycuru de. Sensoriamento remoto no ensino básico de Geografia: Definindo novas estratégias. Rio de Janeiro, RJ: APED, 2012. 228p.

CASTRO, Wallas de Souza; FERREIRA, Manuel Eduardo. Bases de dados geográficas digitais no Brasil: formatos, acessibilidade e aplicações. Goiânia, GO: Ateliê Geográfico, 2012.v. 6, n. 1, p.92-122.

DEWEY, John. How we think. Courier Corporation, 1997. 224p.

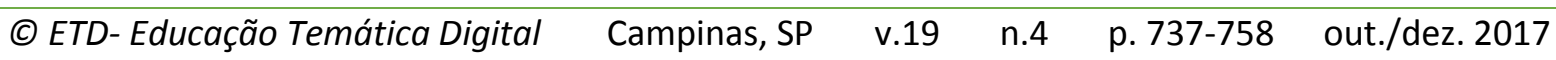


DI MAIO, Angelica Carvalho. Geotecnologias digitais no Ensino Médio: Avaliação prática de seu potencial. Rio Claro, SP. Tese de Doutorado. Universidade Estadual Paulista Júlio de Mesquita Filho - Campus Rio Claro, 2004, 189p.

DI MAIO, Angelica Carvalho; FRANCISCO, Cristiane Nunes; LEVY, Carlos Henrique; PINTO, Cláudia Andréa Lafayette; NUNES, Eusébio Abreu; CARVALHO, Marcus Vinícius Alves de; DORNELAS, Thaís da Silva. GEOIDEA - Geotecnologia como instrumento da inclusão digital e educação ambiental. In: SIMPÓSIO BRASILEIRO DE SENSORIAMENTO REMOTO, XIV Natal, 2009. Anais...Natal, RN: SBSR. 2397-2404.

DI MAIO, Angelica Carvalho; SETZER, Alberto W. Educação, Geografia e o desafio de novas tecnologias. Revista Portuguesa de Educação, 2011. v. 24, n.2, p. 211-241.

FAYAD, Mohamed E.; SCHIMIDT, Douglas C. Object-oriented application frameworks. Commun. ACM, 1997. v. 40, n.10, p.32-38.

FAYAD, Mohamed E. Introduction to the computing surveys electronic symposium on objectoriented application frameworks. ACM Comput. Surv. 2000. v. 32, n.1, p. 1-9.

FLORENZANO, Teresa Gallotti. Iniciação em sensoriamento remoto. 2ª ed. São Paulo, SP: Oficina de Textos, 2007. 97p.

FREIRE, Paulo. Extensão ou comunicação? 7.ed., Rio de Janeiro, RJ: Paz e Terra, 1983. 93p.

FREIRE, Paulo. Pedagogia da autonomia: Saberes necessários à prática educativa. 25ạ ed. São Paulo, SP: Paz e Terra, 1996. 54p.

FREIRE, Fernanda M. P.; VALENTE, José Armando. Aprendendo para a vida: os computadores na sala de aula. São Paulo, SP: Cortez, 2001. 239 p.

GONZÁLEZ, José Antônio Moreiro; BARQUIN, Beatriz Ainhize Rodríguez; MARTUL, David García; PINTO, Adilson Luiz. Bibliotecas digitales y open source software. Inf. \& Soc. 2006. v.16, n.1, p. 13-21.

GOVONI, Darren. Java Application Frameworks. New. York, John Wiley \& Sons, 1999. 432p.

JENSEN, JENS F. Interactivity. Nordicom Review, Nordic research on media and communication review, 1998. v.19, n.2, p.185-204.

LIMA, Suely Franco Siqueira de; MELLO, Eliana Maria Kalil; FLORENZANO, Gallotti Florenzano. Tutorial sobre o uso de Geotecnologias no estudo de Bacias Hidrográficas para professores da Educação Básica. In: SIMPÓSIO BRASILEIRO DE SENSORIAMENTO REMOTO, XIII, Florianópolis, SC: 2007. Anais...Florianópolis, SC: SBSR, 2007. p.1515-1522. 
LIMA, Suely Franco Siqueira de. Material didático para educação básica com uso de geotecnologias - estudo do impacto ambiental da hidrelétrica de Paraibuna. Taubaté, SP. Dissertação de Mestrado. Universidade de Taubaté - UNITAU, 2008. 91p.

LIMA, Suely Franco Siqueira de; FLORENZANO, Gallotti Florenzano; MELLO, Eliana Maria Kalil; MOREIRA, José Carlos. Formação de professores da educação básica em geotecnologias. In: SIMPÓSIO BRASILEIRO DE SENSORIAMENTO REMOTO, XIV, Natal, RN: 2009. Anais...Natal, RN: SBSR, 2009. p. 2437-2444.

LIMA, Suely Franco Siqueira de; FLORENZANO, Gallotti Florenzano; MORAES, Elisabete Caria; COSTA, Dilene Fernandes Machado. Sensoriamento remoto no estudo da dengue com alunos do ensino fundamental. In: SIMPÓSIO BRASILEIRO DE SENSORIAMENTO REMOTO, XV, Curitiba, PR: 2011. Anais...Curitiba, PR: SBSR, 2011. p.3400-3407.

LIMA, Suely Franco Siqueira de; MATIAS, Lindon Fonseca; FLORENZANO, Gallotti Florenzano. Uso de SIG e jogo eletrônico no Atlas Ambiental da cana-de-açúcar no Estado de São Paulo. In: ENCONTRO NACIONAL DA ASSOCIAÇÃO NACIONAL DE PÓS-GRADUAÇÃO E PESQUISA EM GEOGRAFIA, X, Campinas, SP: 2013.Anais...Campinas, SP: ENANPEGE, 2013. p.2484-2496.

LIMA, Suely Franco Siqueira de. Proposta metodológica para a construção de atlas escolar digital e de jogo interativo na escola. Tese (Doutorado em Geografia) - Universidade Estadual de Campinas (Unicamp), Campinas, SP: 2015.

LIMA, Suely franco Siqueira de; MATIAS, Lindon Fonseca; FLORENZANO, Teresa Gallotti. Contribuição na elaboração de atlas escolares para a aprendizagem ubíqua. Caminhos de Geografia, Uberlândia, MG: 2015. v. 16, n. 56, p. 22-36.

LOPES, Daniel de Queiroz; VALENTINI, Carla Beatris. Mídias locativas e realidade mixada: a produção de sentidos sobre o digital-virtual a partir da cartografia com suporte das tecnologias digitais. Educação Unisinos, v.16, n.3, 2012. p.205-214.

MARTINELLI, Marcelo. Os mapas da geografia. In: CONGRESSO BRASILEIRO DE CARTOGRAFIA, XXI, Macaé, 2005.Anais...Macaé, RJ: CBC, 2005. p.01-09.

MARTINELLI, Marcelo. O Atlas do estado de São Paulo. Boletim Goiano de Geografia. v.27, n.2, 2007. p.51-77.

MATIAS, Lindon Fonseca. Sistema de informações geográficas (SIG): teoria e método para representação do espaço geográfico. São Paulo, SP, Tese de Doutorado. Universidade de São Paulo (USP), 2001. 325p.

MATOS, Ecivaldo de Souza. Dialética da Interação Humano-Computador: tratamento didático do diálogo midiatizado. Tese de Doutorado. Universidade de São Paulo (USP). 2013, 271p. 
MENEGUETTE, Arlete Aparecida Correia. Cartografia no século 21: revisitando conceitos e definições. Revista Geografia e Pesquisa, 2012. v.6, n.1, p.06-32.

MORAES, Elisabete Caria; FLORENZANO, Gallotti Florenzano. Avaliação do curso de uso escolar de sensoriamento remoto no estudo do meio ambiente. In: SIMPÓSIO BRASILEIRO DE SENSORIAMENTO REMOTO, XIII, Florianópolis, 2007. Anais... Florianópolis, SC: SBSR, 2007. p.1531-1536.

OLIVEIRA, Thaiane Moreira de. Mapeamento das competências cognitivas no 'gameplay' de Jogos de Realidade Alternada. Contemporânea. v.10, n.1, 2012. p01-19.

NUNES, Alexandre Gasparotti. Uso de smartphones na prática educativa: Experiência e processo criativo. ETD - Educ. Temat. Digit. v.18, n.4, 2016. p. 889-902.

PASSOS, Mônica Regina da Silva; FILHO BARROS, Marcello Benigno; PASSOS, Iana Daya. Desenvolvimento de uma aplicação SIG-Web voltada ao turismo. In: SIMPÓSIO BRASILEIRO DE CIÊNCIAS GEODÉSICAS E TECNOLOGIAS DA GEOINFORMAÇÃO, II, Recife, 2008.

Anais...Recife, PE: SIMGEO, 2008. p. 000-000.

PINO, Angel. O Biólogo e o cultural nos processos cognitivos. In: E. F. MORTIMER; A. L. B. SMOLKA. (Org.) Linguagem, Cultura e Cognição: reflexões para o ensino e a sala de aula. Belo Horizonte, MG: Autêntica, 2001. p. 21-50.

PRIMO, Alex; BRAMBILLA, Ana Maria. Software social e construção do conhecimento. Redes.Com, n. 2, 2005. p. 389-404.

RAMOS, Cristhiane da Silva. Visualização cartográfica e cartografia multimídia: conceitos e tecnologias. São Paulo, SP: Editora UNESP, 2005. 179 p.

SAMPAIO, Adriany de Ávila Melo; MENEZES, Paulo Márcio Leal de; SAMPAIO, Antônio Carlos Freire. Avaliação de Atlas Geográfico escolar digital e impresso. Brazilian Geographical Journal: Geosciences and Humanities research médium. v.4, n.1. Ibituba, ES: 2013. p.275287.

SILVA, Christian Nunes da. A cartografia em sala de aula na explicação do espaço geográfico. ACTA Geográfica. v.7, n.15, 2013. p.55-68.

SOUZA, Adriana Alves Novais; SCHNEIDER, Henrique Nou. Tecnologias digitais na formação inicial docente: Articulações e reflexões com uso de redes sociais. ETD - Educ. Temat. Digit. v.18, n.2, 2016. p. 418-436.

SOUZA, Wendson de Oliveira; ESPINDOLA, Giovana Mira de; PEREIRA, Alessandro Rhadamek Alves; SÁ, Lucilene Antunes Correia Marques de. A realidade aumentada na apresentação de produtos cartográficos. Bol. Ciênc. Geod. v. 22, n.4, Curitiba, PR: 2016 . p.790 - 806.

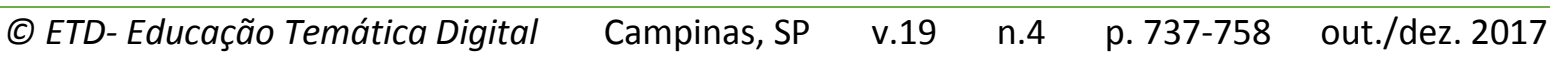


TORI, Romero. A presença das tecnologias interativas na educação. Revista de Computação e Tecnologia da PUC-SP. v. II, n.1, 2010. p.4-16.

UNITED STATES OF AMERICA. Association for Computing Machinery. Curriculum Development Group. Curricula for human-computer interaction. New Yourk: ACM, 1992. p.162.

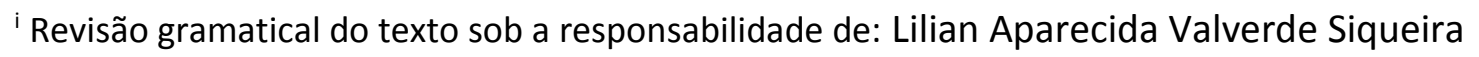

